\title{
Solar radiation modelling and measurement techniques in Lafia Zone, Nasarawa state, Nigeria
}

\author{
Andah Mamman ${ }^{1,2 *}$ Umaru Ibrahim ${ }^{1,3}$, Mustapha M. Idris ${ }^{1,4}$, \\ Abdullahi A. Mundi ${ }^{1}$ and Musa U. Sarki ${ }^{1,5}$ \\ ${ }^{1}$ Department of Physics, Nasarawa State University, Keffi Nigeria \\ ${ }^{2}$ Department of Electrical/Electronics Engineering Technology, \\ Nasarawa State Polytechnic, Lafia Nigeria \\ ${ }^{3}$ Department of Physics, Federal University, Lafia Nigeria \\ ${ }^{4}$ Department of Physics, Federal University of Technology, Minna, Nigeria \\ ${ }^{5}$ Department of Physics, Federal University of Agriculture, Markudi, Nigeria \\ *Corresponding author: andahmamman@gmail.com
}

DOI: https://doi.org/10.37134/ejsmt.vol7.1.6.2020

Received: 27 February 2020; Accepted: 30 May 2020; Published: 04 June 2020

\begin{abstract}
The number of solar radiations measuring stations in Nigeria has been observed not to effectively describe the necessary variability; as such prediction models are necessary for estimation of solar radiation values using readily available meteorological variables. In this study, solar radiation parameters were determined for Lafia zone, Nasarawa State, Nigeria. Twelve (12) location were carefully selected to avoid sunshine and wind obstruction using a systematic random sampling technique. Three-hour daily measurement (12.00 pm to $2.00 \mathrm{pm})$ was done on three $12 \mathrm{~V}, 5 \mathrm{~W}$ solar panels using a pyranometer and the output was estimated using the Angstrom-Prescott Regression Equation. The continuity in the assembled system was measured using an Avometer. The result revealed that solar radiation intensity was found to range from $165.5 \mathrm{~W} / \mathrm{m}^{2}$ to $298.6 \mathrm{~W} / \mathrm{m}^{2}$ with the mean value of $241.24 \mathrm{~W} / \mathrm{m}^{2}$.The highest global solar radiation value of $29.8 \mathrm{MJ} / \mathrm{m}^{2}$ was observed in April while the lowest value of $16.5 \mathrm{MJ} / \mathrm{m}^{2} \mathrm{was}$ observed in August. The extraterrestrial solar radiation was found to range from $9.06 \mathrm{MJ} / \mathrm{m}^{2}$ in August to 26.60 $\mathrm{MJ} / \mathrm{m}^{2}$ in February with average value of $20.96 \mathrm{MJ} / \mathrm{m}^{2}$. The atmospheric transmission coefficient over the year is found to range from 0.7 in July and September to 1.4 in December. The obtained atmospheric transmission coefficient determined for the year (2019) is a good indication for solar radiation application in Lafia geo-political zone, Nasarawa State. The performance of the developed model is observed to imply that it can be used to predict global solar radiation for Lafia zone in Nasarawa State.
\end{abstract}

Keywords: Solar radiation, Pyranometer, Angstrom-Prescott Regression Equation, and monthly average daily global radiation.

\section{INTRODUCTION}

The driving force for all atmospheric processes is the sun. Solar radiant intensity is the input of energy expression upon the planet. Therefore, in other to understand and quantify its value and distribution correctly, it is important that initial understanding and modeling of any other thermodynamic or dynamic process in the earth-ocean-atmosphere system are properly done [1]. Some applications of solar energy such as photovoltaic system sizing, modeling, and design of solar crop dryers require the vast knowledge of global solar insolation. The intensity of solar radiation per day is usually one of the variables collected by meteorological stations in tropical Africa, Nigeria especially [2].

Solar irradiation is the total solar energy falling on a surface and it can be related to the solar irradiance by considering the area under solar irradiance versus time curve (Muhammad, 1983). Measurements or estimation of the solar irradiation, in a specific location, is key to study the optimal 
design and to predict the performance and efficiency of photovoltaic (PV) systems; the measurements can be done based on the solar irradiance (solar power in $\mathrm{W} / \mathrm{m}^{2}$ ) in that location $[1,3,4]$.

The performance of a PV system, module or array depends on many factors, one of which is the solar irradiance the solar panels receive during the day (peak sun-hours) $[3,4,5]$. There are devices specifically designed to measure solar irradiance, such as the pyranometer and the irradiance meter [1, 3, 6-9]. These devices can measure irradiance with high accuracy and cover a wide spectral range.

It is an established fact that solar radiation prediction models are necessary, because the density and number of solar radiations measuring stations cannot describe the necessary variability in most cases [10]. It is then understandable that new models and improvements to existing modeling techniques are continually proposed which intend to improve estimates of solar radiation values with the use of more readily available meteorological variables $[10,11,12]$.

The most widely accepted and used numerical method of determining the monthly average daily global solar radiation in a location is the Angstrom linear type model. The regression constants of this equation ' $a$ ' and ' $b$ ' are specific to a particular location. Constants ' $a$ ' and ' $b$ ' refer to the fractions of the extraterrestrial radiation that is diffused (scattered) and direct (beam) respectively. The determination of these constants enables the determination of the global solar radiation for the location whose solar radiation information is required $[13,14]$.

Nasarawa State falls under the koppens climatic classification of AW, that is, tropical rainy climate with distinct dry season in winter. The rainy season span a period of seven months (April to October) with an annual rainfall of about $1200-2000 \mathrm{~mm}$. The southern part tends to record more rainfall than northern part. The temperature is moderate in January as a result of the harmattan influence. The northern part however tends to be colder than the southern part of the state. The January temperature ranges between $22.5-25{ }^{\circ} \mathrm{C}$ for the north and $25-27.5{ }^{\circ} \mathrm{C}$ for the south. The spatial variation in temperatures is greatly reduced by July when the whole state will be under the influence of rains. Humidity is generally high during the rainy seasons, about $95 \%$ in parts of the state. The figure drops to about 55\% for the dry season. Sunshine hours are high between January to April and decreases between May through to October because of the effects of cloud. There is a noticeable increase in sunshine hours again by November [15]. Therefore, this study is aimed at measurement and estimation ofsolar radiation for Lafia geo-political zone, Nasarawa State, Nigeria.

\section{MATERIALS AND METHOD}

Twelve (12) location within Lafia zone in Nasarawa State were carefully selected so that there was no sunshine obstruction and no obstructions of wind. Plumb Lime was used to level the ground horizontally and vertically and a piece of 3D Mode Golden Dream Time Compass. Three 12V, 5W Solar panels (poly) were used, and a three days measurement interval was made using the Secondary Standard Pyranometer which was placed on top of the panels and the output was taken from the pyranometer and was estimated using the Angstrom-Prescott Regression Equation. A 3D Mode Golden Dream Time Compass was used to determine the angle of the panels inclined, and was used to take latitude and altitude of the measurement area. The continuity in the assembled system was measured using an Avometer.

Global and diffuse solar radiation was measured with the help of a thermoelectric pyranometer. Basically, pyranometer is consisting of a blackened-thin surface supported inside a relatively massive well-polished case. When solar radiation falls on this surface, the temperature of the surface rises until its rate of loss of the heat by all causes is equal to the rate of gain of heat by radiation. This rise in temperature sets up a thermal e.m.f. which is measured on a recording millivoltmeter or recorder. The pyranometer is calibrated and a certificate is provided by the manufacturer. For quality data of solar radiation pyranometer have to be calibrated at regular intervals and required proper maintenance. 
Solar radiation energy data(s) were collected in twelve different locations across Lafia geo - political zones in Nasarawa State. Measurements were taking using different angles viz; $0^{\circ}, 30^{\circ}, 60^{\circ}$ and $90^{\circ}$ with a view to determine the best angle for solar energy collection for each zone in the state.

\section{MODEL FOR SOLAR RADIATION}

The solar radiation data collected from Lafia zone in Nasarawa State were model using Prescott angstrom liner equation with a view to bring out a new model. In the new model a and $\mathrm{b}$ were developed taking into consideration in order to make it possible to calculate, the monthly mean of daily global solar radiation $\bar{H}\left(\mathrm{MJ} / \mathrm{m}^{2}\right)$, on a horizontal surface from monthly average daily total insolation on an extraterrestrial horizontal surface as per the following relation[1]:

$\frac{\bar{H}}{\bar{H}_{0}}=a+b\left(\frac{\bar{s}}{\bar{s}_{0}}\right)$

and

$\bar{H}_{0}=\frac{24(60) K_{s c} I_{r}}{\pi}=\left(\omega_{s} \sin \varphi \sin \delta+\cos \varphi \cos \delta \sin \omega_{s}\right)$

$I_{r}=1+0.033 \cos \frac{2 \pi}{360} N$

$\delta=0.409 \sin \left(\frac{2 \pi}{360} N-1.39\right)$

$\omega_{s}=\cos ^{-1}(-\tan \varphi \tan \delta)$

$N=\frac{24 \omega_{s}}{\pi}$

where

$\bar{H}=$ monthly average of the daily global radiation on a horizontal surface $\left(\mathrm{MJ} / \mathrm{m}^{2}\right)$

$\bar{H}_{0}=$ extraterrestrial solar radiation on the 15 th of month $\left(\mathrm{MJ} / \mathrm{m}^{2}\right)$

$\bar{s}=$ monthly average daily bright sunshine hours,

$\bar{S}_{0}=$ maximum possible monthly average daily sunshine hours or the day length,

$a$ and $b=$ regression constants,

$K_{S C}=$ solar constant $=0.0820\left(\mathrm{MJ} / \mathrm{m}^{2} / \mathrm{min}\right)$,

$I_{r}=$ inverse relative distance earth - sun,

$\delta=$ solar declination $(\mathrm{rad})$,

$\varphi=$ latitude of the place (rad)

$\omega_{s}=$ sunset hour angle $(\mathrm{rad})$,

$N=$ day number from January $1^{\text {st }}$,

$\frac{\bar{s}}{\bar{s}_{0}}=$ fractionof maximum possible numbers of bright sunshine hours, and 
$\frac{\bar{H}}{\bar{H}_{0}}=$ atmospheric transmission coefficient, commonly known as clearness index.

\section{RESULTS AND DISCURSION}

The climatological data for Lafia geo-political zone in Nasarawa State were determine for its usefulness and application in understanding local weather parameters. The measured solar radiation for the months of January to December and the geo-points for Lafia geo-political zone in Nasarawa State are presented in Table 1 . The best position or the angle which attract highest solar harvest is the angle of $30^{\circ}$ with a mean solar harvest of mean solar intensity of $241.34 \mathrm{~W} / \mathrm{m}^{2}$. The solar radiation intensity was found to range from 165.5 (August) to $298.6 \mathrm{~W} / \mathrm{m}^{2}$ (April) with the mean value of $241.24 \mathrm{~W} / \mathrm{m}^{2}$. The highest global solar radiation value of $27.6 \mathrm{MJ} / \mathrm{m}^{2}$ was observed in May while the lowest value of $14.0 \mathrm{MJ} / \mathrm{m}^{2}$ was in September.

Table 1: Mean measured global solar radiation $(\bar{H})$ and solar intensity from the month of January to December 2019 for Lafia geo-political zone.

\begin{tabular}{|c|c|c|c|c|c|c|}
\hline S/n & Latitude & Longitude & Month & Season & $\begin{array}{l}\text { Solar } \\
\text { Intensity } \\
\left(\mathbf{W} / \mathbf{m}^{2}\right)\end{array}$ & $\bar{H}\left(\mathbf{M J} / \mathbf{m}^{2}\right)$ \\
\hline 1 & $8^{\circ} 71^{\prime} 30^{\prime \prime}$ & $8^{\circ} 61^{\prime} 60^{\prime \prime}$ & January & Dry & 273.3 & 24.0 \\
\hline 2 & $8^{\circ} 28^{\prime} 18^{\prime \prime}$ & $8^{\circ} 14^{\prime} 09^{\prime \prime}$ & February & Dry & 257.42 & 21.0 \\
\hline 3 & $8^{\circ} 23^{\prime} 35^{\prime \prime}$ & $8^{\circ} 21^{\prime} 19^{\prime \prime}$ & March & Dry & 291.9 & 24.1 \\
\hline 4 & $8^{\circ} 32^{\prime} 17^{\prime \prime}$ & $8^{\circ} 16^{\prime} 01^{\prime \prime}$ & April & Dry & 298.6 & 26.3 \\
\hline 5 & $8^{\circ} 28^{\prime} 59^{\prime \prime}$ & $8^{\circ} 2^{\prime} 20^{\prime \prime}$ & May & Rainy & 276.84 & 27.6 \\
\hline 6 & $8^{\circ} 20^{\prime} 9^{\prime \prime}$ & $9^{\circ} 15^{\prime} 0^{\prime \prime}$ & June & Rainy & 256.6 & 19.74 \\
\hline 7 & $8^{\circ} 6^{\prime} 0^{\prime \prime}$ & $9^{\circ} 7^{\prime} 60^{\prime \prime}$ & July & Rainy & 173.3 & 14.0 \\
\hline 8 & $8^{\circ} 46^{\prime} 9^{\prime \prime}$ & $8^{\circ} 22^{\prime} 02^{\prime \prime}$ & August & Rainy & 165.5 & 12.4 \\
\hline 9 & $8^{\circ} 16^{\prime} 60^{\prime \prime}$ & $8^{\circ} 49^{\prime} 0^{\prime \prime}$ & September & Rainy & 180.6 & 14.4 \\
\hline 10 & $8^{\circ} 10^{\prime} 40^{\prime \prime}$ & $8^{\circ} 6^{\prime} 0^{\prime \prime}$ & October & Rainy & 206.9 & 15.9 \\
\hline 11 & $8^{\circ} 7^{\prime} 60^{\prime \prime}$ & $8^{\circ} 48^{\prime} 0^{\prime \prime}$ & November & Dry & 236.9 & 19.3 \\
\hline 12 & $8^{\circ} 14^{\prime} 4^{\prime \prime}$ & $8^{\circ} 07^{\prime} 01^{\prime \prime}$ & December & Dry & 277.0 & 22.6 \\
\hline Mean & & & & & 241.24 & 20.11 \\
\hline
\end{tabular}

Solar radiation in Lafia geo-political zone, Nasarawa state, Nigeria was measured, and a new model was developed using Angstrom-Prescott model equation. From the above analysis, the model constants of 'a' and ' $b$ ' were 0.06 and 0.55 respectively. The model equation developed is as stated below:

$$
\bar{H}=\bar{H}_{0}\left[0.06+0.55\left(\frac{\bar{s}}{\bar{s}_{0}}\right)\right]
$$

One of the best parameters to estimate the available solar radiation for a particular place is the sun. The mean monthly number of the daily hours of bright sunshine for periods of January to December 2019 are presented in Table 2. Measurement of solar radiation of Lafia geo-political zone in Nasarawa State was 
taken for 3hour (from $12.00 \mathrm{pm}$ to $3.00 \mathrm{pm}$ ) every day which serve as the monthly average daily bright sunshine hours and 12 hours which serve as the maximum possible monthly average daily sunshine hours from January to December 2019 was recorded in Table 2. The variation in seasons (rainy and dry) was not taken into consideration in this study. The extraterrestrial solar radiation $\left(\overline{\boldsymbol{H}}_{\mathbf{0}}\right)$ were found to range from $9.06 \mathrm{MJ} / \mathrm{m}^{2}$ in August to $26.60 \mathrm{MJ} / \mathrm{m}^{2}$ in February with average value of $20.96 \mathrm{MJ} / \mathrm{m}^{2}$ (Table 2). These values are slightly below that obtained by Adesina et al. [14].

Table 2: Monthly average daily sunshine, extraterrestrial solar radiation, fraction of possible bright sunshine hours, and atmospheric transition coefficient.

\begin{tabular}{lccccc}
\hline Month & $\overline{\boldsymbol{S}}$ & $\overline{\boldsymbol{s}}_{\mathbf{0}}$ & $\overline{\boldsymbol{H}}_{\mathbf{0}}\left(\mathbf{M} \mathbf{J} / \mathbf{m}^{\mathbf{2}}\right)$ & $\overline{\overline{\boldsymbol{H}}}$ & $\overline{\overline{\boldsymbol{s}}}$ \\
& (hours) & (hours) & & $\overline{\overline{\boldsymbol{H}}}_{\mathbf{0}}$ & $\overline{\overline{\boldsymbol{S}}_{\mathbf{0}}}$ \\
\hline January & 3.00 & 12.00 & 23.18 & 1.0 & 0.250 \\
February & 3.00 & 12.00 & 26.60 & 0.8 & 0.250 \\
March & 3.00 & 12.00 & 23.17 & 1.0 & 0.250 \\
April & 3.00 & 12.00 & 24.51 & 1.2 & 0.250 \\
May & 3.00 & 12.00 & 24.77 & 1.1 & 0.250 \\
June & 3.00 & 12.00 & 23.25 & 0.8 & 0.250 \\
July & 3.00 & 12.00 & 19.43 & 0.7 & 0.250 \\
August & 3.00 & 12.00 & 9.06 & 1.3 & 0.250 \\
September & 3.00 & 12.00 & 20.49 & 0.7 & 0.250 \\
October & 3.00 & 12.00 & 20.61 & 0.8 & 0.250 \\
November & 3.00 & 12.00 & 20.10 & 1.0 & 0.250 \\
December & 3.00 & 12.00 & 16.33 & 1.4 & 0.250 \\
& & & 20.96 & & \\
& & & & &
\end{tabular}

Figure 1 shows the graphical representation of the monthly average of the daily global radiation $(\overline{\boldsymbol{H}})$ and extraterrestrial solar radiation $\left(\overline{\boldsymbol{H}}_{\mathbf{0}}\right)$ which confirms the strong agreement between them. There were some discrepancies between them with the monthly average of the daily global radiation higher in the month of January, March, April, May, and December, while extraterrestrial solar radiation higher in the month of February, June, July, September, October, and November. This could be as a result of weather variation as suggested by Adesina et al. [14]. 


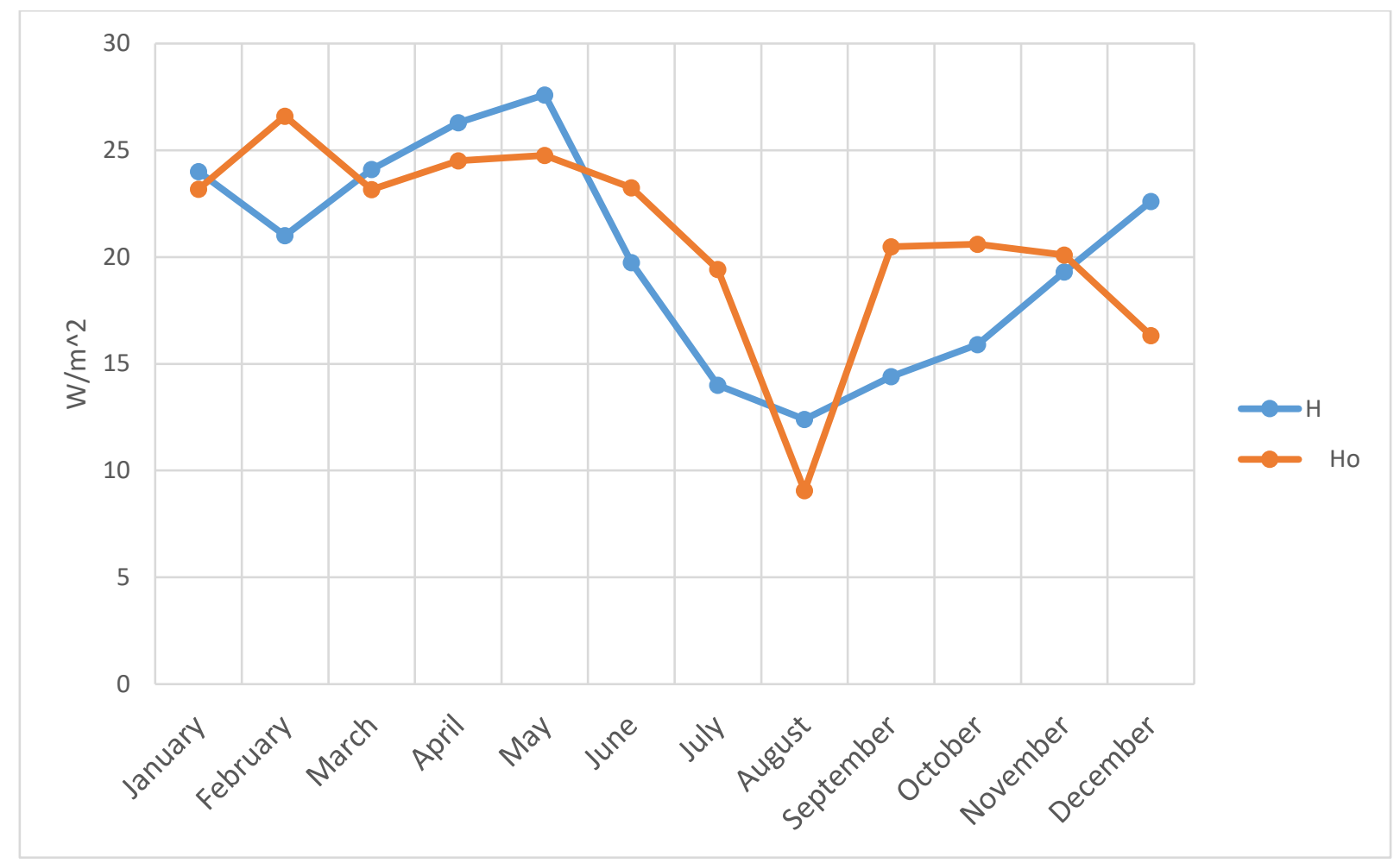

Figure 1: Comparison between monthly average of the daily global radiation $(\bar{H})$ and extraterrestrial solar radiation $\left(\bar{H}_{0}\right)$ for the month of January to December 2019.

The variation of cloudiness is primarily responsible for the day to day variation of the daily total radiation during the whole month [2]. The atmospheric transmission coefficient or clearness index over the year is found to range from 0.7 in July and September to 1.4 in December. In dry season months, in April, the sky is very clear with atmospheric transmission coefficient of 1.1 which corresponds to the highest value of solar irradiance recorded value of $29.8 \mathrm{MJ} / \mathrm{m}^{2}$ which allows on the average nearly $60 \%$ of the extraterrestrial radiation to reach the earth's surface.

Table 3 presents a comparison of measured Monthly Daily Global Solar Radiation $(\bar{H})$ of the present study and published data from studies done in Nigeria. The Monthly Daily Global Solar Radiation obtained for Lafia zone in Nasarawa State is in agreement with data obtained for Bauchi, Makurdi, and Kano. Enugu and Abuja have lower value while Maiduguri has the highest value of Monthly Daily Global Solar.

Table 3: Comparison between measured Monthly Daily Global Solar Radiation $(\bar{H})$ of other states in Nigeria and Present Study.

\begin{tabular}{lll}
\hline State in Nigeria & Monthly Daily Global Solar Radiation $(\overline{\boldsymbol{H}})$ & Source \\
\hline Maiduguri & 5.5 & {$[16]$} \\
Enugu & 0.004 & {$[16]$} \\
Abuja & 0.0546 & {$[16]$} \\
Makurdi & 0.626 & {$[17]$} \\
Kano & 0.465 & {$[18]$} \\
Bauchi & 0.70 & {$[13]$} \\
Nasarawa & 0.61 & Present Study \\
\hline
\end{tabular}

In general, Nigeria has a tropical climate with variable rainy and dry seasons, depending on location. It is hot and wet most of the year in the southeast but dry in the southwest and farther inland. A savanna climate, with marked wet and dry seasons, prevails in the north and west, while a steppe climate with little precipitation is found in the far north [19]. 


\section{CONCLUSION}

The solar radiation measurement was carried out using a pyranometer for Lafia zone, Nasarawa State for the year 2019, which is most suitable for this purpose. The climatological data such as the monthly average of daily global radiation, extraterrestrial solar radiation and solar radiation intensity were determined on hourly basis. A model using Prescott angstrom liner equation was used with the regression constant ' $a$ ' and ' $b$ ' obtained as 0.06 and 0.55 respectively. This study indicates efficient utilization and prospects of application of solar energy in Lafia zone, Nasarawa State. The bright sunshine between $12.00 \mathrm{pm}$ to $3.00 \mathrm{pm}$ every day confirmed from the high atmospheric transmission coefficient or clearness index throughout the year is a good indication for solar radiation application in Lafia zone, Nasarawa State. It is observed that the performance of the developed model implies that it can be used to predict global solar radiation for Lafia zone in Nasarawa State.

\section{REFRENCE}

[1] Pandey C. K. \&Katiyar A. K. Solar Radiation: Models and Measurement Techniques. Journal of Energy, 2013, 3(1), $1-8$. http://dx.doi.org/10.1155/2013/305207

[2] Adekunle A. O., Emmanuel C. O., Stephen B. O., Olugbenga F. Analysis of Global Solar Irradiance over Climatic Zones in Nigeria for Solar Energy Applications. Journal of Solar Energy, 2015, 5(1), 1-9. http://dx.doi.org/10.1155/2015/819307

[3] Al-Addous M., Dalala Z., Class C.B., Alawneh F., Al-Taani H. Performance analysis of off- grid PV systems in the Jordan valley. Renew Energy, 2017, 113, 930 - 941.

[4] Ma W.W., Rasul M.G., Liu G., Li M., Tan X.H. Climate change impacts on techno-economic performance of roof PV solar system in Australia. Renew Energy, 2016, 88, 430 - 438.

[5] Akinyele D.O., Rayudu R.K. Comprehensive techno-economic and environmental impact study of a localised photovoltaic power system (PPS) for off-grid communities. Energy Convers. Manag., 2016, 124, 266279.

[6] Poudyal K.N., Bhattarai B.K., Sapkota B.K., Kjeldstad B., Karki N.R. Estimation of Global Solar Radiation using Pyranometer and NILU-UV Irradiance Meter at Pokhara Valley in Nepal. Journal of Inst. Eng., 2014, 9, $69-78$.

[7]Seaward A. Solar Survey Multifunction Solar Irradiance Meters, 2017. Available online: http://www.seawardsolar.com/downloads/survey_100_and_200r_datasheets_international_v1.3.pdf (accessedon 14 January 2018).

[8] Zeqiang B., Wenhua L., Yizhuo S., Xiaolei H., Wei C. Research on performance test method of silicon pyranometer. In Proceedings of the 2013 IEEE 11th International Conference on Electronic Measurement \&Instruments, Harbin, China, 16 - 19, August 2013.

[9] Nagamine F., Shimokawa R., Miyake Y., Nakata M., Fujisawa K. Calibration of Pyranometers for the photovoltaic device field. Japan Journal of Applied Physics, 1990, 29, 516 - 521.

[10] Donatelli M., Bellocchi G., Fontana F. RadEst3.00: software to estimate daily radiation data from commonly available meteorological variables. European Journal of Agronomy, 2003, 18(3-4), 363-367.

[11] Younes S., MuneerT. Improvements in solar radiation models based on cloud data. Building Services Engineering Research and Technology, 2006, 27(1), $41-54$.

[12] Safi S., ZeroualA., Hassani M. Prediction of global daily solar radiation using higher order statistics. Renewable Energy, 2002, 27 (4), 647-666.

[13] Burari W.F., Sambo S.A. Model for the Prediction of Global Solar Radiation for Bauchi using meteorological data. Renewable Energy, 2001, 9(1\&2), 30 - 33.

[14] Adesina M. A., IbrahimJ. S., IortyerH. A. A Simulation Model for Estimating Solar Radiation of Nasarawa, Nasarawa State - Nigeria. British Journal of Applied Science \& Technology, 2016, 17(2), 1-8, Article no. BJAST.24603. ISSN: 2231-0843, NLM ID: 101664541.

[15] Binbol, N.L. \& Marcus, N.D. Geography of Nasarawa State: A study of Flora and Fauna. Information from Ministry of Agriculture and Natural Resources, Lafia. 2000, https://irepos.unijos.edu.ng/jspui/bitstream/123456789/1441/1/Geography\%20of\%20Nasara wa0001\% 20\%288\%20files\%20merged\%29.pdf

[16] Osueke, C. O \& Ezugwu, C. A. K. Study of Nigeria Energy Resources and Its Journal of Scientific \& Engineering Research, 2011, 2(10), $210 \quad-215$.

Consumption. International 
[17] Audu M. O., Utah U. E., Ugwanyi J. U. Estimation of Global Solar Radiation over Asian Journal of Applied Sciences, 2014, 2 (2), 111 - 118.

[18] Auwal, M. \& Darma, T. H. Estimation of Global Solar Radiation for Kano State Nigeria Meteorological Data. Journal of Applied Physics, 2014, 6(6), 19 - 23.

[19]Reuben K.U., Ade A.J.F. Nigeria. Encyclopedia https://www.britannica.com/place/Nigeria/Climate
Makurdi, Nigeria.

Based on

Britannica, inc.

inc. 2020 . 